\title{
Improving Capacity, Stiffness and Pneumatic Hammer Stability of Aerostatic Thrust Bearing Using Damping Orifice and Virtual Recess
}

Wei Ma ( $\sim$ jx04319@126.com )

Shanghai Institute of Satellite Engineering

Xianglong Kong

Shanghai institute of satellite engineering

Yi Xu

Shanghai institute of satellite engineering

Original Article

Keywords: Aerostatic thrust bearing, Damping orifice, Virtual recess, Pneumatic hammer stability

Posted Date: March 26th, 2020

DOI: https://doi.org/10.21203/rs.3.rs-19435/v1

License: (c) (i) This work is licensed under a Creative Commons Attribution 4.0 International License.

Read Full License 


\section{Title page}

\section{Improving Capacity, Stiffness and Pneumatic Hammer Stability of Aerostatic Thrust Bearing Using Damping Orifice and Virtual Recess}

Wei Ma, born in 1984, is currently an engineer at Shanghai Institute of Satellite Engineering, Shanghai, China. He received his PhD degree in Instrumentation Science and Technology from Harbin Institute of Technology, China, in 2016. His research interests include the design of aerostatic bearing and its stability, Principles of Mechanical Design, numerical analysis and optimization for complex air bearings.

Tel: +86-021-24236641; E-mail: jx04319@126.com

XiangLong Kong, born in 1986, is currently Design Engineer at Shanghai Institute of Satellite Engineering, China. He received the Master degree in Signal and Information Processing from Shanghai Academy of Spaceflight Technology, China, in 2010. His research interests include the design of satellite, simulation of space environment, numerical analysis and optimization for Signal and Information.

Yi Xu, born in 1988, is currently Design Engineer at Shanghai Institute of Satellite Engineering, China. He received the Master degree in Communication and Information System from University of Electronic Science and Technology of China, China, in 2011. His research interests include the design of satellite, numerical analysis and optimization for aerostatic bearing.

Corresponding author: Wei Ma E-mail: jx04319@126.com 


\title{
ORIGINAL ARTICLE
}

\section{Improving Capacity, Stiffness and Pneumatic Hammer Stability of Aerostatic Thrust Bearing Using Damping Orifice and Virtual Recess}

\author{
Wei Ma $・$ XiangLong Kong • Yi Xu
}

Received June xx, 201x; revised February xx, 201x; accepted March xx, 201x

(c) Chinese Mechanical Engineering Society and Springer-Verlag Berlin Heidelberg 2017

\begin{abstract}
An aerostatic thrust bearing is designed using damping orifice and virtual recess. Finite element simulations and measurements are performed and results indicate that with damping orifice and virtual recess, the maximum capacity of the designed aerostatic bearing increases from $1590 \mathrm{~N}$ to $2285 \mathrm{~N}$ and its maximum stiffness increases from $106 \mathrm{~N} / \mu \mathrm{m}$ to $145 \mathrm{~N} / \mu \mathrm{m}$, while the range of pneumatic hammer decreases from $8.5 \mu \mathrm{m}$ to $4.5 \mu \mathrm{m}$ at 4 bar. It is therefore concluded that damping orifice and virtual recess are one of the means which can be used to improve the capacity, stiffness and pneumatic hammer stability of aerostatic bearing.
\end{abstract}

Keywords: Aerostatic thrust bearing $•$ Damping orifice $•$ Virtual recess $\bullet$ Pneumatic hammer stability

\section{Introduction}

Aerostatic bearings are widely used in ultra-precision machining equipment and measurement equipment because of their extremely high accuracy, lower friction and no wear. However, it is very difficult to design an aerostatic bearing with high capacity, stiffness and pneumatic hammer stability for a limited bearing area. Many researchers concentrate on improving the stiffness and stability of aerostatic bearings[1]. The capacity and stiffness of aerostatic bearings can be improved by increasing gas supply pressure, number of grooves[2] and orifices[3-5], or selecting multiple[6-7], and porous restrictors[8]. Some work has been done using RNM method about the

$\square$ Wei Ma

jx04319@126.com

Shanghai Institute of Satellite Engineering, Shanghai 201108, China influence of the length and depth of the grooves on the static and dynamic characteristics of aerostatic bearings[9-10]. However, the increase in the gas supply pressure and the number of grooves reduces the stability of pneumatic hammer[11]. The increase in the number of orifice results in a significant increase in mass flow. Double-pad aerostatic bearing[12], multiple-micro-

moles aerostatic bearing[13-15], porous aerostatic bearing, aerostatic bearing with flexible members[16] and aerostatic bearing with active control[17] can also be used to improve the stiffness, but the utilization of these aerostatic bearings is very complicated. The characteristics of porous bearings are closely related to porous materials, which have some shortcomings, such as unstable performance, less than 8 microns working gas film, great difficulty in accurate analysis and so on. The utilization of micro-array bearings is very complicated, and its working gas film thickness is generally less than 10 microns, so it is not suitable for high working film applications. Further the stability of pneumatic hammer on aerostatic bearings has not been considered above.

The effect of pneumatic hammer on the performance of aerostatic bearings is closely related to pressure fluctuation[18-19], and it can be characterized using the damping characteristics of the bearings[20-21]. Thus, the damping characteristics of aerostatic bearings are very important for the study on their dynamic stabilities. The high damping characteristics of air spring is therefore introduced into the design of an aerostatic bearing to improve its stability significantly[22]. However, pneumatic hammer is a kind of self-excited instability due to the compressibility of air, which occurs in aerostatic bearings 
with recess easily. The damping of aerostatic bearings cannot be improved by increasing their bearing areas in a space-constrained situation. Therefore, we concentrate on the design of aerostatic bearings with damping orifice and virtual recess and investigate the influence of damping orifices on the pneumatic stability. A rectangular aerostatic thrust bearing is designed using damping orifices and virtual recesses so that a good balance can be achieved among the capacity, stiffness and pneumatic hammer stability. The designed aerostatic bearing is numerically and experimentally investigated to prove its effectiveness in improving its capacity, stiffness and pneumatic hammer stability.

\section{Numerical Calculation}

\subsection{Aerostatic Bearing Model}

As shown in Figure 1 and Figure 2, aerostatic bearings can be designed with and without damping orifice and virtual recess. The structural parameters of the aerostatic bearing with damping orifice and virtual recess, such as $L, H, L o$, $L_{d}, l_{w}, H o, H_{w}, H_{d}, l x$, and $l z$ are shown in Figure 2.

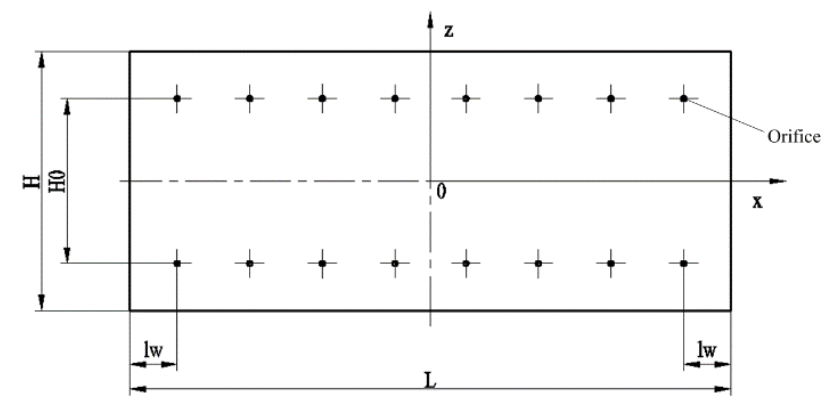

Figure 1 Aerostatic thrust bearing without damping orifice and virtual recess

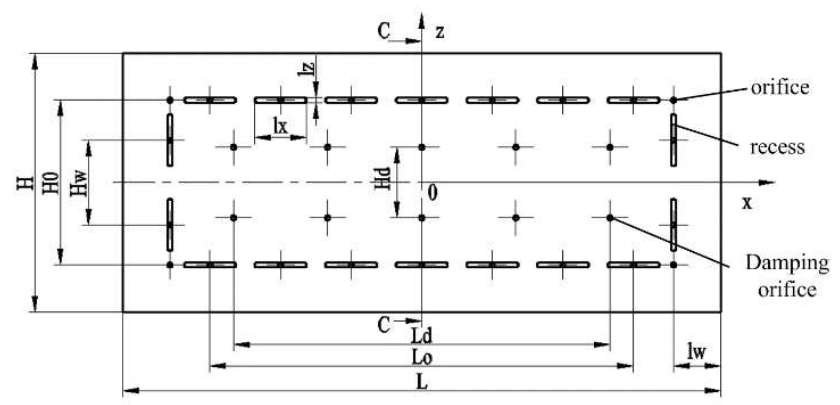

Figure 2 Aerostatic thrust bearing with damping orifice and virtual recess

The capacity and stiffness of aerostatic bearings can be improved by providing a ring of shallow recesses around its central land to create a high pressure region which is virtual recess named by Rowe[23]. However, because of its volume effect, pneumatic hammer occurs in the aerostatic bearing. So an array of annular orifices is introduced in the high pressure region. As shown in Figure 3, an air spring consisting of a high pressure region, annular orifices and gas supply passages is used to improve the stability of pneumatic hammer. Then the annular orifices could be named damping orifices. Table 1 shows the structural parameters of the aerostatic bearing with damping orifice and virtual recess. Then the parameters of $n_{l}, n_{2}, d_{l}, d_{2}$ are shown in appendix.

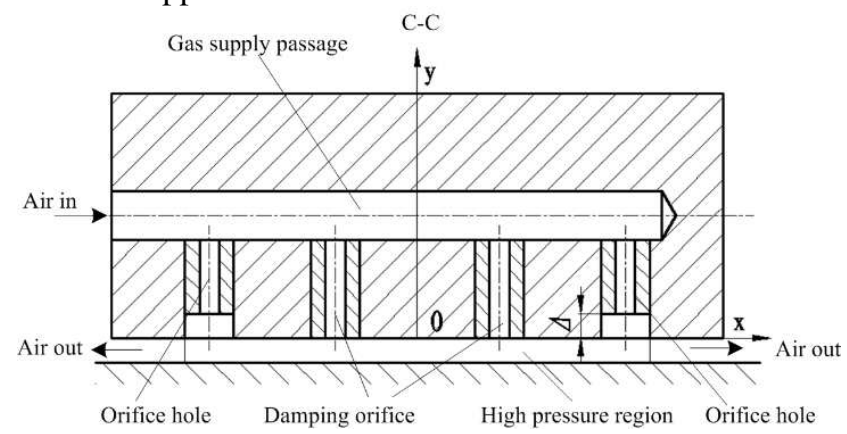

Figure 3 Cross-sectional view of the designed aerostatic thrust bearing

Table 1 Dimensions of the designed aerostatic bearing

\begin{tabular}{ll}
\hline parameter & value \\
\hline$L \times H(\mathrm{~mm} \times \mathrm{mm})$ & $127 \times 55$ \\
$L o(\mathrm{~mm})$ & 90 \\
$L d(\mathrm{~mm})$ & 80 \\
$l w(\mathrm{~mm})$ & 10 \\
$H o(\mathrm{~mm})$ & 35 \\
$H w(\mathrm{~mm})$ & 18 \\
$H d(\mathrm{~mm})$ & 15 \\
$l x \times l z(\mathrm{~mm} \times \mathrm{mm})$ & $12 \times 1$ \\
$n_{l}$ & 22 \\
$n_{2}$ & 10 \\
$d l(\mathrm{~mm})$ & 0.2 \\
$d 2(\mathrm{~mm})$ & 0.2 \\
\hline
\end{tabular}

\subsection{Numerical Calculation}

Considering the effect of orifices, Generalized Reynolds equation used to analyze the capacity and stiffness of an aerostatic bearing is given by:

$$
\begin{aligned}
& \frac{\partial}{\partial x}\left(h^{3} p \frac{\partial p}{\partial x}\right)+\frac{\partial}{\partial z}\left(h^{3} p \frac{\partial p}{\partial z}\right)= \\
& \frac{12 \eta p_{a} \rho v}{\rho_{a}} \delta_{i}+12 \eta \frac{\partial(p h)}{\partial t}+6 \eta\left[\frac{\partial p h\left(u_{1}+u_{2}\right)}{\partial x}+\frac{\partial p h\left(w_{1}+w_{2}\right)}{\partial z}\right] \\
& \delta_{i}=\left\{\begin{array}{l}
1 ; \\
0 ; \quad \text { where exists feed orifice }
\end{array}\right.
\end{aligned}
$$

As shown in Eq. (1), the physical meaning of Reynolds equation is the product the change rate of mass 
flow per unit area and unit time in the computational domain with a common factor of $12 \eta p_{a} / \rho_{a}$.

The pressure $P_{d}$ through orifices and the damping orifice is calculated as follows:

$$
\begin{array}{ll}
m_{\text {in }}=A p_{0} \phi \psi \sqrt{2 \rho_{a} / p_{a}} \\
\psi= \begin{cases}{\left[\frac{k}{2}\left(\frac{2}{k+1}\right)^{(k+1) /(k-1)}\right]^{1 / 2}} & \frac{p_{d}}{p_{0}} \leq\left(\frac{2}{k+1}\right)^{k /(k-1)} \\
\left\{\frac{k}{k-1}\left[\left(\frac{p_{d}}{p_{0}}\right)^{2 / k}-\left(\frac{p_{d}}{p_{0}}\right)^{(k+1) / k}\right]\right\}^{1 / 2} & \frac{p_{d}}{p_{0}}>\left(\frac{2}{k+1}\right)^{k /(k-1)}\end{cases}
\end{array}
$$

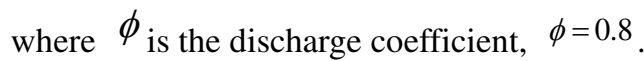

According to the numerical calculation, the Reynolds equation for damping orifice and recess is given as[24]:

$$
\begin{gathered}
\frac{\partial}{\partial x}\left(h^{3} p \frac{\partial p}{\partial x}\right)+\frac{\partial}{\partial z}\left(h^{3} p \frac{\partial p}{\partial z}\right)=6 \eta\left[\frac{\partial p h\left(u_{1}+u_{2}\right)}{\partial x}+\frac{\partial p h\left(w_{1}+w_{2}\right)}{\partial z}\right]- \\
\frac{12 \eta p_{a} \rho v}{\rho_{a}} \delta_{i}-12 \eta \sum_{i_{i}=1}^{n_{c}}\left(\Delta_{i_{k}}+\Delta_{0_{i_{k}}}\right) \frac{p_{d i}}{d t} \delta_{i_{k}}+12 \eta \frac{\partial(p h)}{\partial t} \\
\delta_{i}= \begin{cases}1 ; & \text { where exists orifice } \\
0 ; & \text { where absents orifice }\end{cases} \\
\delta_{i_{k}}= \begin{cases}1 ; & \text { where exists pocket besides with orifice } \\
0 ; & \text { where absents pocket }\end{cases}
\end{gathered}
$$

For an aerostatic bearing, the velocities in directions $\mathrm{x}$ and $\mathrm{z}$ are zero, that is:

$$
u_{1}=u_{2}=0, \quad w_{1}=w_{2}=0
$$

For the static characteristics of an aerostatic thrust bearing, the differential on time is zero, that is:

$$
\frac{p_{d i}}{d t}=0 \frac{\partial(p h)}{\partial t}=0
$$

In summary, the Reynolds equation for damping orifices and recesses could be expressed as follows:

$$
\begin{aligned}
& \frac{\partial}{\partial x}\left(h^{3} p \frac{\partial p}{\partial x}\right)+\frac{\partial}{\partial z}\left(h^{3} p \frac{\partial p}{\partial z}\right)+\frac{12 \eta p_{a} \rho v}{\rho_{a}} \delta_{i}=0 \\
& \delta_{i}= \begin{cases}1 ; & \text { where exists orifice } \\
0 ; & \text { where absents } \text { orifice }\end{cases}
\end{aligned}
$$

The Reynolds equation is reconstructed by using the Galerkin residual method and is discretized by the infinite element as follows.

$$
\begin{gathered}
\sum_{e \in \Omega_{h}} \iint_{\Delta_{e}} h^{3}\left(\frac{\partial p^{2}}{\partial x} \frac{\partial \delta p}{\partial x}+\frac{\partial p^{2}}{\partial z} \frac{\partial \delta p}{\partial z}\right) d x d z= \\
\sum_{e \in \Omega_{h}+\Omega_{d}} \iint_{\Delta_{e}} \frac{24 \eta p_{a}}{\rho_{a}} \rho_{i} v \delta_{i} \delta p d x d z
\end{gathered}
$$

where, $e_{\text {is }}$ the element, $\Delta_{e}$ is the area of element, $\Omega_{d}$ is the calculate domain of recess and $\Omega_{h}$ is the calculate domain of film thickness. The capacity and stiffness of the aerostatic bearing are calculated as follows:

$$
\begin{aligned}
& W(h)=\sum_{e \in \Omega_{h}+\Omega_{k}} \int_{\Delta_{e}} p d x d z-A p_{a} \\
& E=\Delta W / \Delta h
\end{aligned}
$$

The capacity and stiffness of the designed aerostatic bearings are numerically investigated using finite element method. 1/4 of the bearing is investigated because of geometric symmetry, and Figure 4 shows the computational meshes. The model has a triangular element and the recesses are made as linear source. By the way, the pressure in recess is considered constant.

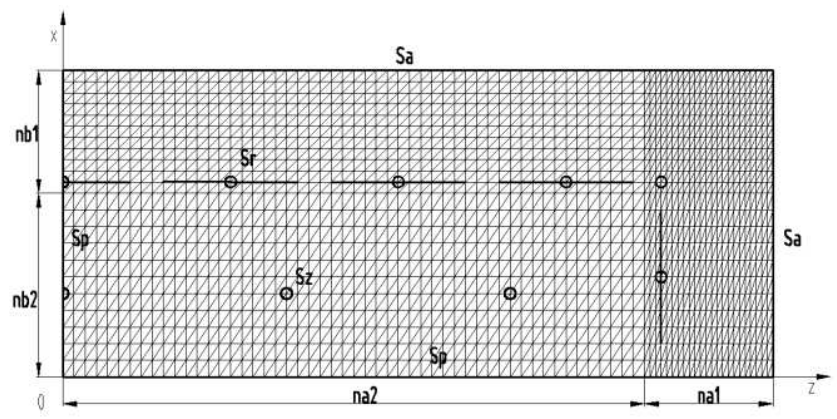

Figure 4 Computational meshes of the aerostatic bearing

At the boundary of the environment pressure ${ }^{S_{a}}$ is:

$$
p=p_{a}
$$

At the symmetric boundary $S_{p}$ is:

$$
\frac{\partial p}{\partial n}=0
$$

At the boundary of the orifice and recess $S_{r}$ is :

$$
p=p_{d i} \text { or } p=p_{d j}
$$

At the boundary of the damping orifice $S_{z}$ is :

$$
p=p_{d k}
$$

The Reynolds equation with damping orifices and recesses is used to solve the pressure distribution in the designed aerostatic bearing with Matlab. Based on future engineering application considerations, the pressure distribution in the aerostatic bearing with a gas supply pressure of 4 bar and a film thickness of $20 \mu \mathrm{m}$ is shown in Figure 5. 


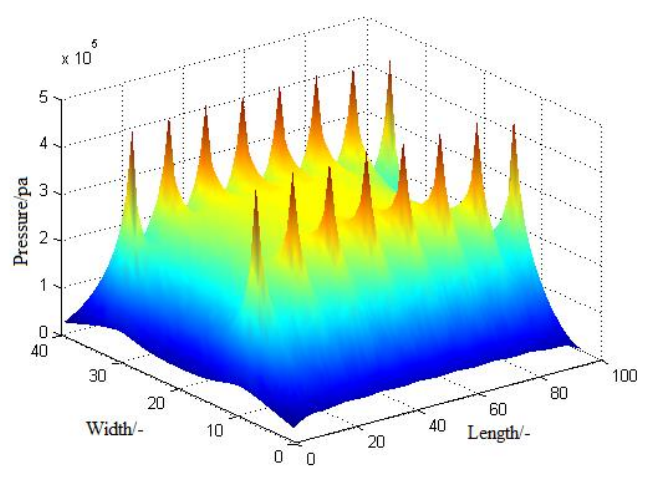

a) Pressure distribution in aerostatic thrust bearing without damping orifice and virtual recess

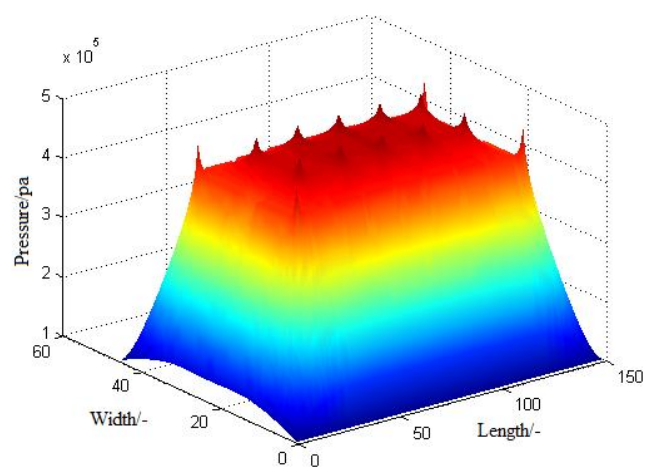

b) Pressure distribution in aerostatic thrust bearing with damping orifice and virtual recess

Figure 5 Pressure distribution in aerostatic thrust bearing at 4 bar with $20 \mu \mathrm{m}$

As shown in Figure 5, there is a high pressure distribution at the center of the designed aerostatic bearing with damping orifice and virtual recess, while there is a big pressure drop at the orifice of the bearing without damping orifice and virtual recess. The capacity of the designed aerostatic bearing with damping orifice and virtual recess achieved by simulation is $795 \mathrm{~N}$ at 4 bar with $20 \mu \mathrm{m}$, and by measurement is $814 \mathrm{~N}$. Therefore it is a good match between the simulation result and measurement result.

\section{Results and Discussion}

Comparison of the designed aerostatic bearings with and without damping orifice and virtual recess on load capacity and stiffness at 4 bar is shown in Figure 6.

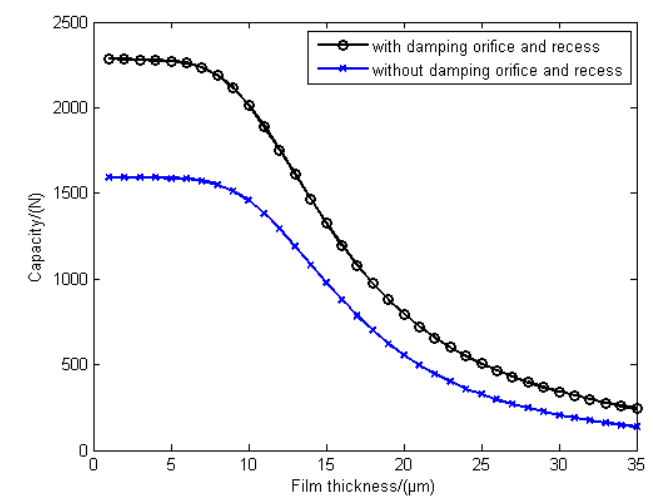

a) Comparison of capacities of aerostatic bearings with and without damping orifice and virtual recess

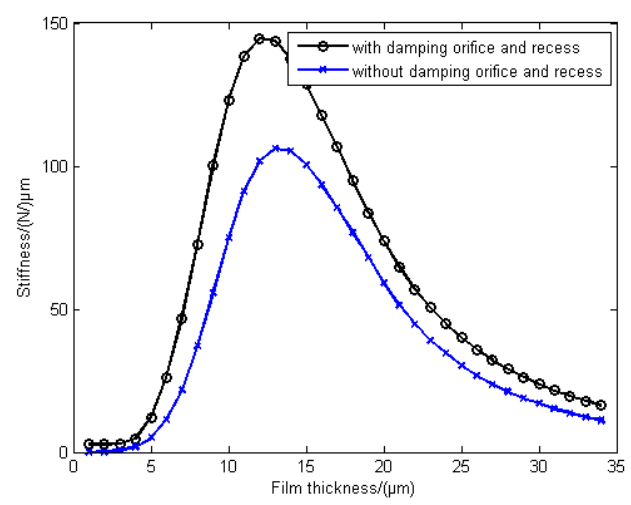

b) Comparison of stiffness of aerostatic bearings with and without damping orifice and virtual recess

Figure 6 Comparison of aerostatic thrust bearings with and without damping orifice and virtual recess at 4 bar

It could be seen in Figure 6 that with damping orifice and virtual recess, the maximum capacity and stiffness of the designed aerostatic bearing increase from $1590 \mathrm{~N}$ to $2285 \mathrm{~N}$, and from $106 \mathrm{~N} / \mu \mathrm{m}$ to $145 \mathrm{~N} / \mu \mathrm{m}$ at 4 bar respectively. Therefore, the capacity and stiffness of the designed aerostatic bearing are significantly improved by adding damping orifice and virtual recess.

The influence of supply pressure, diameter of orifice and number of damping orifices on the designed aerostatic bearing with damping orifice and virtual recess is analyzed. The relationship between supply pressure and static characteristic of the designed aerostatic bearing is shown in Figure 7. 


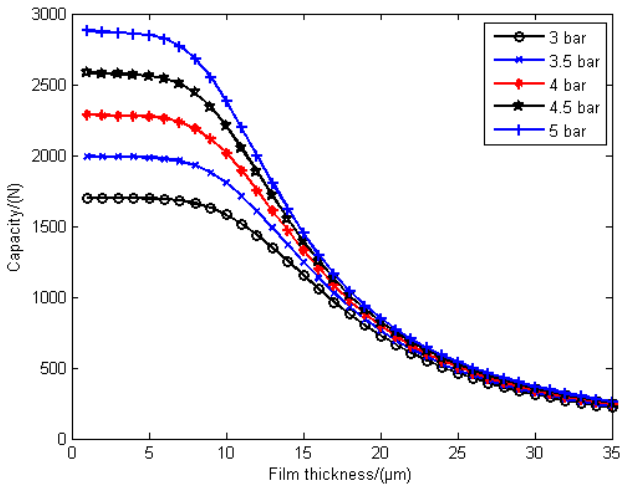

a) Relationship between load capacity and film thickness for different gas supply pressure

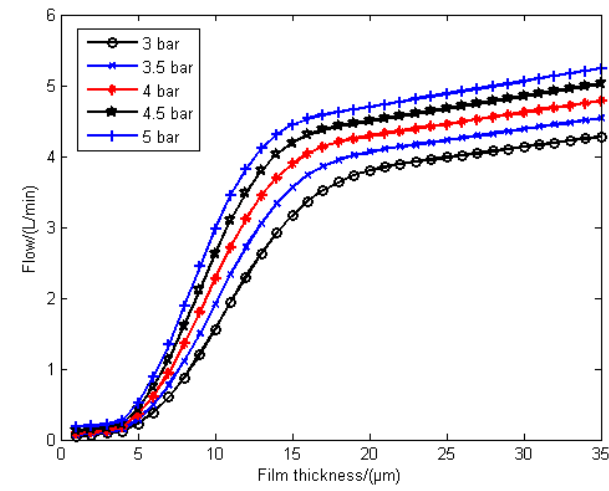

b) Relationship between flow and film thickness for different gas supply pressure

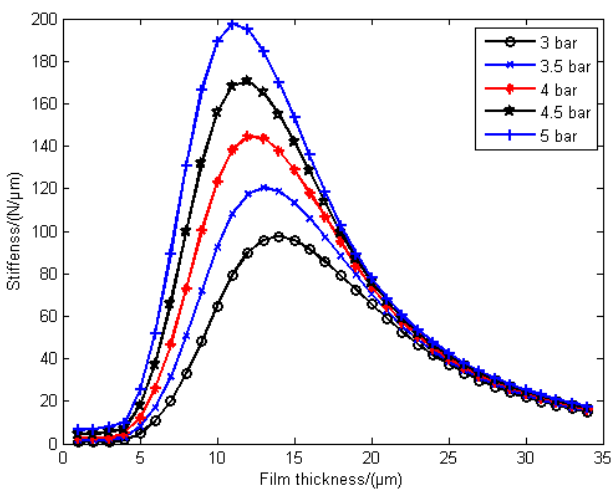

c) Relationship between stiffness and film thickness for different gas supply pressure

Figure 7 Relationship between supply pressure and static characteristics of designed aerostatic bearing

As shown in Figure 7(a) and 7(b), with the same supply pressure, the capacity of the designed aerostatic bearing gradually decreases but the mass flow gradually increases as the film thickness increases. For the same film thickness, the capacity of the designed aerostatic bearing and the mass flow increase as the supply pressure increases. It can be seen from Figure 7(c) that, the stiffness of the designed aerostatic bearing increases as the supply pressure increases. The maximum stiffness of $987 \mathrm{~N} / \mu \mathrm{m}$ occurs at supply pressure of 3 bar and a film thickness of $14 \mu \mathrm{m}$. The maximum stiffness of $197 \mathrm{~N} / \mu \mathrm{m}$ occurs at supply pressure of 5 bar and a film thickness of $11 \mu \mathrm{m}$. This means that the maximum stiffness of the designed aerostatic bearing moves toward the smaller film thickness

The relationship between orifice diameter and static characteristic of aerostatic bearing at 3.5 bar is shown in Figure 8.

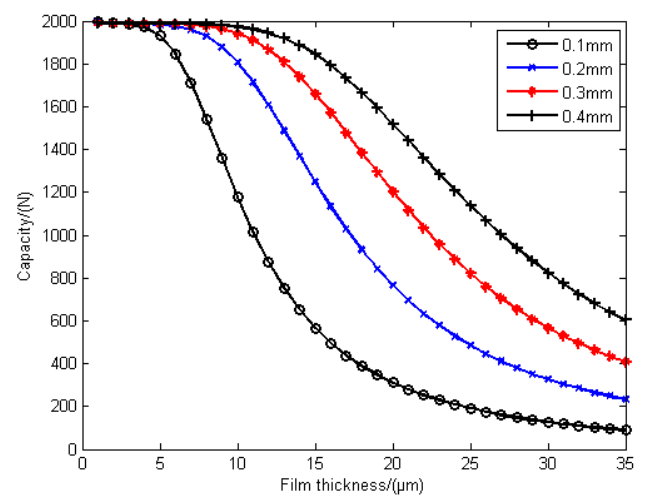

a) Relationship between capacity and film thickness for different orifice diameter

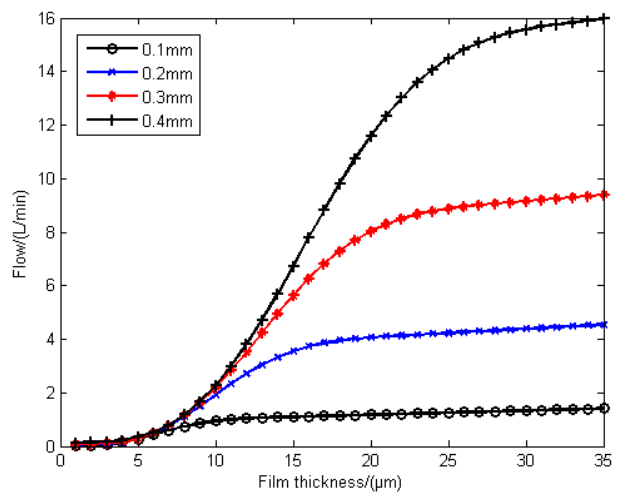

b) Relationship between flow and film thickness for different orifice diameter 


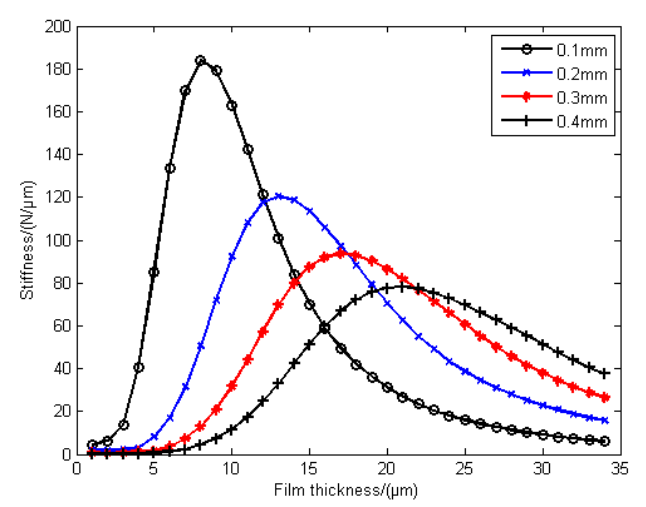

c) Relationship between stiffness and film thickness for different orifice diameter

Figure 8 Relationship between orifice diameter and static characteristic of aerostatic bearing at $3.5 \mathrm{bar}$

As shown in Figure 8, the maximum capacity is approximately constant, and the capacity and mass flow of the designed aerostatic bearing gradually decrease and the maximum stiffness gradually increases with the decrease in the orifice diameter for the same film thickness. The maximum mass flow is $1.41 \mathrm{~L} / \mathrm{min}$ for the orifice diameter of $0.1 \mathrm{~mm}$ and the maximum mass flow is $15.96 \mathrm{~L} / \mathrm{min}$ for the orifice diameter of $0.4 \mathrm{~mm}$. In conclusion, the lower mass flow and higher stiffness of the designed aerostatic bearing can be achieved for a small film thickness by reducing the orifice diameter, which needs a bearing surface with average roughness of 0.1 microns.

The relationship between number of damping orifices and static characteristic of aerostatic bearing at 3.5 bar is shown in Figure 9.

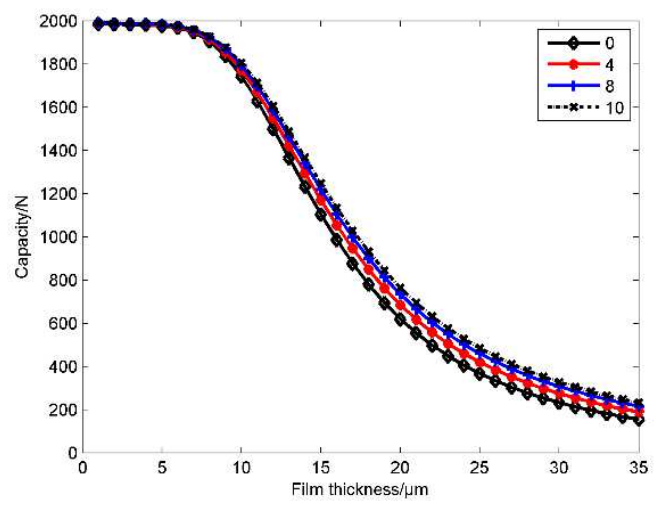

(a) Relationship between capacity and film thickness for different number of damping orifices

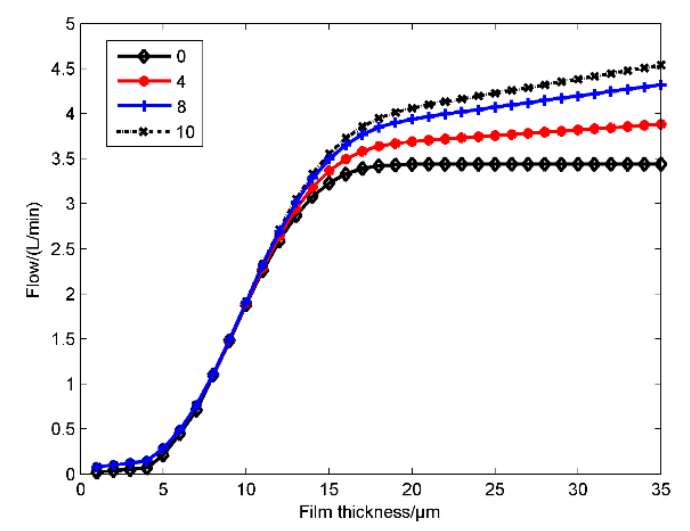

(b) Relationship between flow and film thickness for different number of damping orifices

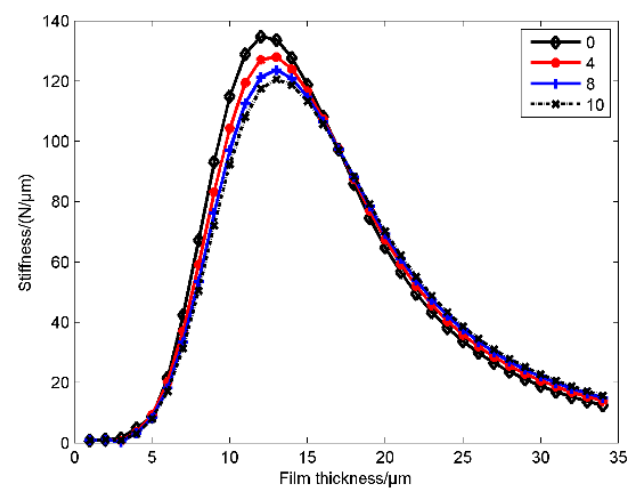

(c) Relationship between stiffness and film thickness for different number of damping orifices

Figure 9 Relationship between number of damping orifices and static characteristic of aerostatic bearing at $3.5 \mathrm{bar}$

It can be seen from Figure 9 that the maximum load capacity is $1985 \mathrm{~N}$ and the maximum stiffness is 133.7 $\mathrm{N} / \mu \mathrm{m}$ at $\mathrm{n}_{1}=0$, while the maximum load capacity is $1990 \mathrm{~N}$ and the maximum stiffness is $120.6 \mathrm{~N} / \mu \mathrm{m}$ at $\mathrm{n}_{1}=10$. Then compare with the influence of supply pressure on the static characteristic of the bearing, adding damping orifices will not cause significant change of load capacity and stiffness.

\section{Experimental Verfication}

The designed aerostatic bearing with damping orifice and virtual recess is shown in Figure 10. It is fabricated with stainless steel to verify the theoretical analysis above. 


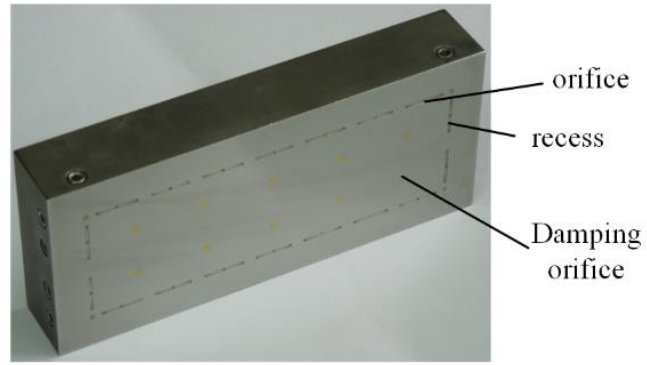

Figure 10 Structure of designed aerostatic thrust bearing

A servo electric cylinder is used to apply the external loads, and a force sensor is used to detect the applied loads. A spherical decoupling is used between the designed aerostatic bearing and the force sensors. Two inductive displacement sensors are used to detect the relative distance between the aerostatic bearing and granite, which is the film thickness. The pressure sensor is arranged as close as possible the aerostatic bearing to avoid the impact of pipeline on the supply pressure. The experimental apparatus is shown in Figure 11. Experiments are run to investigate the load capacity and pneumatic hammer stability of the aerostatic bearing with and without damping orifices and virtual recesses at 4 bar.

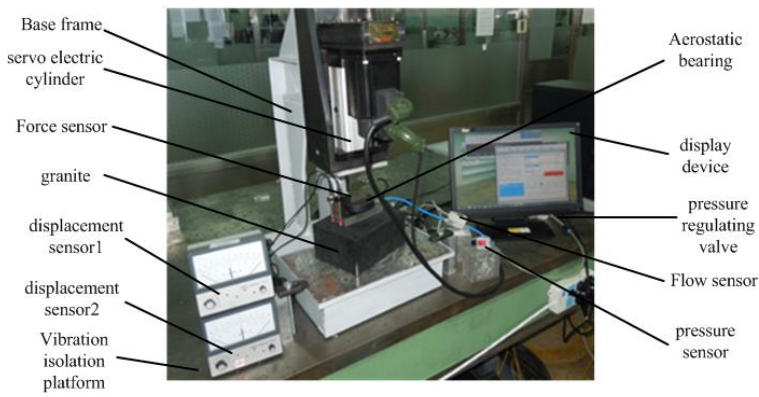

Figure 11 Experimental set-up for the designed aerostatic thrust bearing

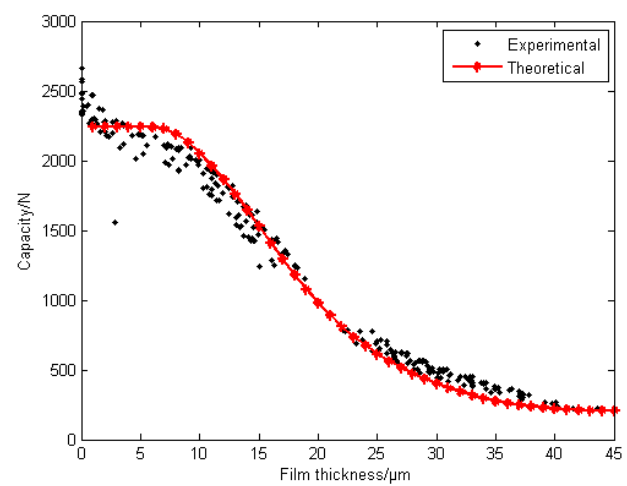

Figure 12 Load capacity of designed aerostatic bearing with 10 damping orifices at 4 bar

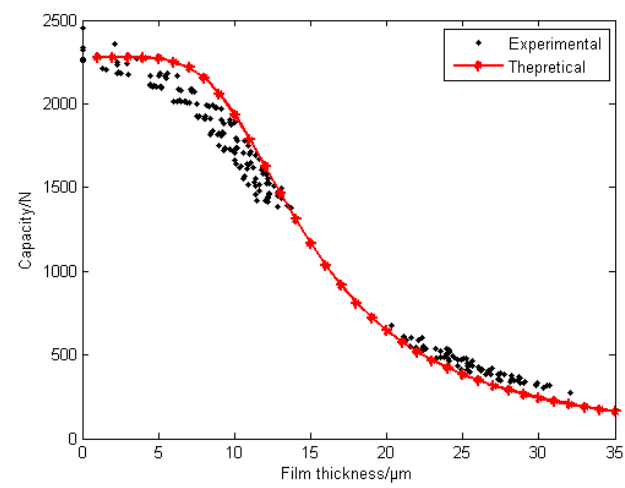

Figure 13 Load capacity of designed aerostatic thrust bearing without damping orifices at 4 bar

As shown in Figure 12 and 13, there is a difference of less than $6 \%$ between experimental and theoretical load capacities at 4 bar. Pneumatic hammer occurs from $18 \mu \mathrm{m}$ to $22.5 \mu \mathrm{m}$ in the designed aerostatic bearing with 10 damping orifices, and from $13 \mu \mathrm{m}$ to $21.5 \mu \mathrm{m}$ in the designed aerostatic bearing without damping orifices. So the damping orifice can be used to improve the stability of pneumatic hammer in an aerostatic bearing.

\section{Conclusions}

An aerostatic thrust bearing is designed using damping orifice and virtual recess to achieve a balance among the load capacity, stiffness and pneumatic hammer stability. It can be seen from the presentation above that:

(1) With damping orifice and virtual recess, the maximum load capacity of the designed aerostatic bearing increases from $1590 \mathrm{~N}$ to $2285 \mathrm{~N}$ and its maximum stiffness increases from $106 \mathrm{~N} / \mu \mathrm{m}$ to $145 \mathrm{~N} / \mu \mathrm{m}$ at 4 bar. So the static characteristics of the designed aerostatic bearing are significantly improved.

(2) The optimum stiffness characteristics of an aerostatic thrust bearing can be achieved by decreasing the number of damping orifice, the orifice diameter, and increasing the supply pressure and the number of recess.

(3) The difference between the experimental and the theoretical results shows that the theoretical analysis is valid. Measurement results indicated that the range of pneumatic hammer decreases from $8.5 \mu \mathrm{m}$ to $4.5 \mu \mathrm{m}$ at 4 bar for the designed aerostatic bearing with damping orifice and virtual recess. Therefore it can be concluded that without significant change in load capacity and stiffness, the pneumatic hammer stability of an 
aerostatic thrust bearing can be improved by adding damping orifice.

\section{Declaration}

\section{Acknowledgements}

The authors sincerely thanks to Professor Yongmeng Liu of Harbin Institute of Technology for his critical discussion and reading during manuscript preparation.

\section{Funding}

Supported by National Natural Science Foundation of China (Grant No. 51805329), and the National key Research and Development Program of China (No. 2016YFB0500801).

\section{Availability of data and materials}

The datasets supporting the conclusions of this article are included within the article.

\section{Authors' contributions}

The author' contributions are as follows: Wei Ma was in charge of the whole trial; Wei Ma, and XianLong Kong wrote the manuscript; $\mathrm{Yi} \mathrm{Xu}$ assisted with sampling and laboratory analyses.

\section{Competing interests}

The authors declare no competing financial interests.

\section{Consent for publication}

Not applicable

\section{Ethics approval and consent to participate}

Not applicable

\section{References}

[1] H L Cui, Y Wang, et al. Numerical Simulation and Experimental Verification of the Stiffness and Stability of Thrust Pad Aerostatic Bearings. Chinese Journal of Mechanical Engineering, 2018,31(23)

[2] J J Du, G Q Zhang, D LIU. Influences of pressure-equalizing groove on the load capacity of externally pressurized gas journal bearings. Journal of Mechanical Engineering, 2012, 48(15): 106-112.

[3] Y Hou, L Y Xie, et al. Study of externally pressurized air thrust bearings with multi-rows supply holes. Journal of Xi'an Jiaotong University, 2000, 34(11): 40-43.

[4] L Tao, X Q Peng, et al. Design optimization of high-precision aerostatic equipment based on orifice Restriction, Proc IMechE Part C: J Mechanical Engineering Science, 2018: 1-16.

[5] Y F Li , Y H Yin, et al. Modeling for optimization of circular flat pad aerostatic bearing with a single central orifice-type restrictor based on CFD simulation. Tribology International, 2017, 109: 206-216.
[6] H L Cui, Y Wang, et al. Numerical analysis of the dynamic performance of aerostatic thrust bearings with different restrictors. Proc IMechE Part J: J Engineering Tribology, 2019, 233(3): 406-423.

[7] F. Colombo1. L, Lentini1.T, et al. Dynamic Characterization of Rectangular Aerostatic Pads with Multiple Inherent Orifices. Tribology International, 2018, 66(133): 1-13.

[8] H Cui, Y Wang, X Yue. Numerical analysis and experimental investigation into the effects of manufacturing errors on the running accuracy of the aerostatic porous spindle. Tribology International, 2018, 118: 20-36.

[9] T Nakamura, S Yoshimoto. Static tilt characteristics of aerostatic rectangular double-pad thrust bearings with compound restrictors. Tribology International, 1996,29(2): 145-152.

[10] M F Chen, Y T Lin. Static behavior and dynamic stability analysis of grooved rectangular aerostatic thrust bearings by modified resistance network method. Tribology International, 2002, 35: 28-38.

[11] X D Chen, J C Zhu, H Chen. Dynamic characteristics of ultra-precision aerostatic bearings. Adv. Manuf, 2013,1: 82-86.

[12] Y R Jeng, S H Chang. Comparison between the effects of single-pad and double-pad aerostatic bearings with pocketed orifices on bearing stiffness. Tribology International, 2013,66: 12-18.

[13] M Miyatake, S Yoshimoto. Numerical investigation of static and dynamic characteristics of aerostatic thrust bearings with small feed holes. Tribology Internationa, 2010, 43: 1353-1359

[14] U Nishio, K Somaya, S Yoshimoto. Numerical calculation and experimental verification of static and dynamic characteristics of aerostatic thrust bearings with small feedholes. Tribology International , 2011,44: 1790-1795.

[15] G Belforte, F Colombo, et al. Experimental analysis of air pads with micro holes. Tribology Transactions, 2013,56: 169-177.

[16] P L Holster, J Jacobs. Theoretical analysis and experimental verification on the static properties of externally pressurized air-bearing pads with load compensation. Tribology International, 1987, 20(5): 276-289.

[17] W P Ge, N M Qi, T Liu. Parameter optimization and analysis of static characteristics for active aerostatic bearing. Journal of Naijing University of Science and Technology. 2007, 31(3): 308-311.

[18] X D Chen, H Chen, et al. Air vortices and nano-vibration of aerostatic bearings. Tribology Letters. 2011, 42(2): 179-183.

[19] Y T Li, Y X Lin, et al. Research on the gas pressure fluctuation characteristics inside an aerostatic thrust bearing with a pocketed orifice-type restrictor. Tribology Transactions, 2014, 57: 28-35.

[20] A Charki, K Diop, et al. Numerical simulation and experimental study of thrust air bearings with multiple orifices. International Journal of Mechanical Sciences, 2014, 72: 28-38.

[21] C H Jia, H J Pang, W S Ma. Analysis of Dynamic Characteristics and Stability Prediction of Gas Bearings, Industrial Lubrication and Tribology, 2017, 69(2): 14-21.

[22] D F Xu, Y Zhu, et al. Improving damping capacity of the aerostatic bearing. Nanotechnology and Precision Engineering, 2010, 8: 84-89

[23] B Rowe. Hydrostatic, aerostatic, and hybrid Bearing Design. Elsevier Ltd. 2012: 35-40

[24] W Ma, J W Cui, Y M Liu, J B Tan. Improving the Pneumatic Hammer Stability of Aerostatic Thrust Bearing with Recess Using Damping Orifices. Tribology International.2016, 103: 281-288. 


\section{Biographical notes}

Wei Ma, born in 1984, is currently an engineer at Shanghai Institute of Satellite Engineering, Shanghai, China. He received his $\mathrm{PhD}$ degree in Instrumentation Science and Technology from Harbin Institute of Technology, China, in 2016. His research interests include the design of aerostatic bearing and its stability, Principles of Mechanical Design, numerical analysis and optimization for complex air bearings.

Tel: +86-021-24236641; E-mail: jx04319@126.com

XiangLong Kong, born in 1986, is currently Design Engineer at Shanghai Institute of Satellite Engineering, China. He received the Master degree in Signal and Information Processing from Shanghai Academy of Spaceflight Technology, China, in 2010. His research interests include the design of satellite, simulation of space environment, numerical analysis and optimization for Signal and Information.

Yi Xu, born in 1988, is currently Design Engineer at Shanghai Institute of Satellite Engineering, China. He received the Master degree in Communication and Information System from University of Electronic Science and Technology of China, China, in 2011. His research interests include the design of satellite, numerical analysis and optimization for aerostatic bearing.

\section{Appendix}

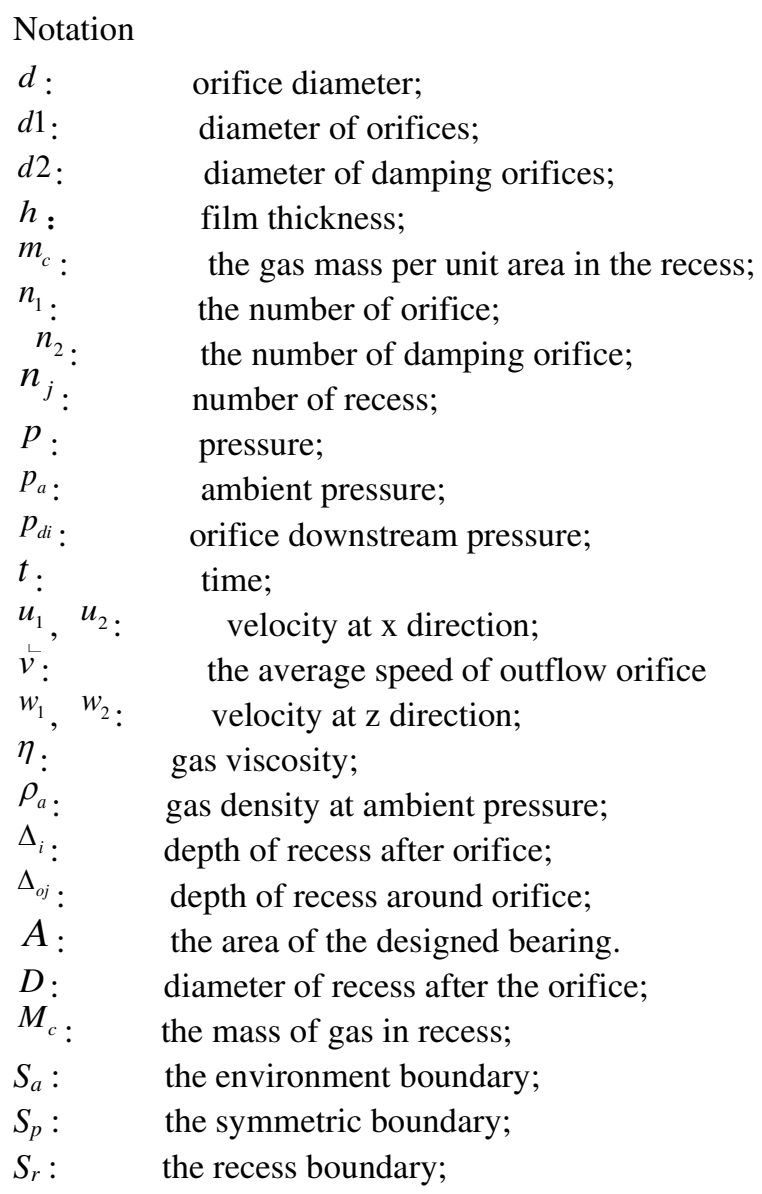

$S_{z}: \quad$ the damping orifice boundary; 